\title{
Homicídio conjugal: comparações quanto ao sexo dos agressores
}

\section{Sex differences in conjugal homicide}

\section{Lucienne Martins Borges*}

Professor Adjunto do Departamento de Psicologia da Universidade Federal do Paraná - UFPR, Curitiba, PR, Brasil

\begin{abstract}
RESUMO
O homicídio conjugal constitui um tipo de homicídio no qual a vítima e o indivíduo homicida estavam (ou haviam estado) afetivamente vinculados um ao outro, quer seja pelo casamento, união estável ou namoro. O objetivo geral desta pesquisa foi o de chegar a uma compreensão mais global da pessoa que cometeu um homicídio conjugal, mais precisamente, verificar como se expressam as diferenças de acordo com o sexo dos agressores. A pesquisa foi realizada com uma amostra de homicídios conjugais cometidos no Estado de Québec, Canadá, entre 1986 e 2000. A partir desse estudo, foi possível estabelecer um perfil dos homens e mulheres que cometeram o homicídio de seu(sua) parceiro(a). A violência conjugal, a separação, o consumo abusivo de álcool e os transtornos psicológicos e psicopatológicos foram algumas das variáveis precursoras observadas e que podem ter um impacto na compreensão e na prevenção desse tipo de passagem ao ato.
\end{abstract}

Palavras-chave: Homicídio conjugal, Crime passional, Violência.

\begin{abstract}
Conjugal homicide refers to homicide in which the victim and the perpetrator were, or had been at some time, legally married, in a common-law relationship, or in a durable intimate relationship. This study seeks to provide a deeper understanding of the perpetrator of conjugal homicide, with particular regard to sex differences in the aggressor, in a sample of participants having committed conjugal homicide in Quebec, Canada, between 1986 and 2000. It was possible to establish a profile of men and of women that had killed their conjugal partner. Several variables pertinent to the understanding and prevention of conjugal homicide were identified, including conjugal violence, alcohol abuse, as well as psychological and psychopathological disorders.
\end{abstract}

Keywords: Spousal homicide, Violence.

\section{Homicídio conjugal: comparações quanto ao sexo dos agressores $^{1}$}

O homicídio conjugal é uma das categorias da classificação dos homicídios (BÉNÉZECH, 1996), representado por um gesto violento, a saber, um ato agressivo que se inscreve no âmbito de uma relação 
conjugal, independentemente de os parceiros estarem juntos ou separados (DUTTON, 2001). Nos Estados Unidos, entre 1976 e 1996, 20.311 homens e 31.260 mulheres foram assassinados pelo(a) parceiro(a) (WEBSDALE, 1999). No Canadá, a mulher corre nove vezes mais risco de ser assassinada pelo seu parceiro do que por um estranho (WILSON; DALY, 1993). No Estado do Québec, entre 1989 e 2000, foram repertoriados 198 homicídios conjugais, sendo 166 $(83,8 \%)$ homicídios perpetrados por homens e $32(16,2 \%)$ por mulheres.

Segundo Fischer (2003), a agressão, sendo ela mortal ou não, pode ser entendida como um acting-out cujo objetivo é a destruição total ou parcial do objeto de amor, ou o ataque físico ou psíquico de uma pessoa ou de um grupo. Os acting-outs podem ser o sinal de uma deterioração da expressão normal do funcionamento mental e a periculosidade se agrava quando estas agressões são associadas a outras situações, tais como as dependências físicas (álcool, drogas), os afetos depressivos ou as condutas suicidas (BERGERET, 1998). Quando ocorrem tais atos agressivos na relação conjugal, eles podem ser o prenúncio de um homicídio conjugal se associados a outros fatores de risco (HOUEL, MERCADER; SOBOTA, 2003; DUTTON, 1998, 2001).

Entre os pesquisadores, observa-se um consenso no que se refere a algumas considerações relacionadas ao homicídio conjugal. Eis algumas delas: 1) presença de violência no histórico da relação conjugal; 2) impacto da separação; 3) abuso de bebidas alcoólicas; 4) prevalência do gesto homicida na população masculina; 5) impacto dos transtornos psicológicos e do perfil de personalidade. Nos homens, o gesto pode ser entendido como sendo a expressão de um sentimento de possessividade ou de rejeição da perda do controle sobre sua parceira. Além disso, o risco de um eventual homicídio aumenta quando o parceiro desconfia que sua parceira esteja sendo infiel ou quando ela decide colocar um termo na relação. Dutton (2001) postulou que os afetos de abandono, ainda mais do que a separação, têm um papel significativo nos homicídios conjugais cometidos por homens. No que se refere às mulheres, elas tendem a cometer um homicídio conjugal em situação de defesa - quando confrontadas à violência do parceiro - para proteger sua própria vida ou a de seus filhos (WEBSDALE, 1999; WILSON; DALY, 1993). Assim, as circunstâncias que conduzem ao homicídio conjugal variam segundo o sexo dos agressores (HOUEL, MERCADER; SOBOTA, 2003; FRIGON; VIAU, 2000).

\section{Objetivo}

O objetivo geral desta pesquisa foi o de apresentar uma compreensão mais global da pessoa que comete um homicídio conjugal e, mais 
precisamente, de verificar como se manifestam as diferenças de acordo com o sexo dos agressores, em uma amostra de homicídios conjugais cometidos no Estado do Québec, Canadá, entre 1986 e 2000. Os homicídios conjugais retidos para o estudo foram os que se relacionavam aos casais heterossexuais, em relação conjugal (namoro, união livre ou casamento) ou separados (depois de ter estado em relação conjugal) no momento do homicídio.

\section{Metodologia}

A pesquisa comportou duas etapas distintas. A primeira etapa consistiu na elaboração e validação do protocolo de pesquisa (Grille

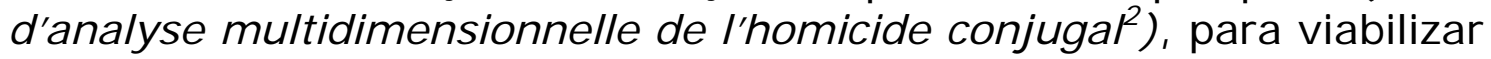
- estudo principal unicamente a partir de arquivos (pesquisa documental). Para tal, baseou-se em um modelo existente para estudos de filicídios (DUBÉ; HODGINS, 1998). A validação do instrumento foi realizada através de entrevistas $(N=10)$ com pessoas que cometeram um homicídio conjugal no Estado do Québec e dos dados do dossiê de cada participante (composto de arquivos do Bureau du Coroner ${ }^{3}$, dos inquéritos da Polícia, dos Fóruns e artigos de periódicos jornalísticos). Uma taxa de concordância global de $81,1 \%$ foi obtida para a totalidade do protocolo, o que permitiu sua utilização como instrumento de medida na segunda etapa da pesquisa.

Essa segunda etapa consistiu em uma análise dos dossiês de cinqüenta e quatro $(N=54)$ participantes, sendo vinte e sete $(N=27)$ do sexo masculino e vinte e sete $(\mathrm{N}=27)$ do sexo feminino. Para tal, um dossiê para cada participante foi construído contendo documentos do Ministério da Segurança Pública, inquéritos policiais, fóruns e artigos jornalísticos. Um acordo interjuiz foi realizado para os 10 primeiros participantes.

\section{Resultados}

A Tabela I oferece uma visão geral do perfil dos homens e mulheres que cometeram homicídio conjugal no Estado do Québec, Canadá.

Tabela I

Perfil dos homens e mulheres que cometeram homicídio conjugal no Estado do Québec

\begin{tabular}{lll}
\multicolumn{1}{c}{ Características } & \multicolumn{1}{c}{ Homens } & \multicolumn{1}{c}{ Mulheres } \\
\hline Naturalidade & canadense & canadense \\
\hline Idade (média) & $\begin{array}{l}41 \text { anos; } \\
\text { mais velho do que a } \\
\text { vítima }\end{array}$ & $\begin{array}{l}40 \text { anos; } \\
\text { mais nova do que a } \\
\text { vítima }\end{array}$ \\
\hline Escolaridade & Menos de 12 anos & Mais de 12 anos \\
\hline Ocupação & Sim & Não \\
\hline
\end{tabular}




\begin{tabular}{|c|c|c|}
\hline $\begin{array}{l}\text { Vínculo com a } \\
\text { vítima }\end{array}$ & $\begin{array}{l}\text { em união estável ou } \\
\text { casado }\end{array}$ & $\begin{array}{l}\text { em união estável ou } \\
\text { casada }\end{array}$ \\
\hline $\begin{array}{l}\text { Local do homicídio } \\
\text { se juntos } \\
\text { se } \\
\text { separados }\end{array}$ & $\begin{array}{l}\text { residência do casal } \\
\text { residência da vítima ou } \\
\text { em outro lugar }\end{array}$ & $\begin{array}{l}\text { residência do casal } \\
\text { residência da vítima }\end{array}$ \\
\hline Período & $\begin{array}{l}\text { Durante a semana, noite } \\
\text { ou madrugada, } \\
\text { primavera-verão }\end{array}$ & $\begin{array}{l}\text { Durante o fim de } \\
\text { semana, à noite, } \\
\text { outono-inverno }\end{array}$ \\
\hline Modo utilizado & $\begin{array}{l}\text { Faca, arma de fogo ou } \\
\text { estrangulação }\end{array}$ & Faca ou arma de fogo \\
\hline $\begin{array}{l}\text { Quem informou as } \\
\text { autoridades }\end{array}$ & Outras pessoas & Outras pessoas \\
\hline Denúncia & $\begin{array}{l}\text { Assumem nas horas ou } \\
\text { dias que se seguem ao } \\
\text { homicídio }\end{array}$ & $\begin{array}{l}\text { Assumem nas horas } \\
\text { que se seguem ao } \\
\text { homicídio }\end{array}$ \\
\hline Ideias suicidas & Sim & Não \\
\hline Álcool & $\begin{array}{l}\text { Problema de consumo } \\
\text { abusivo de álcool }\end{array}$ & $\begin{array}{l}\text { Problema de consumo } \\
\text { abusivo de álcool }\end{array}$ \\
\hline Violência conjugal & Instigador & Vítima ou instigadora \\
\hline $\begin{array}{l}\text { Motivações para } \\
\text { cometer o } \\
\text { homicídio }\end{array}$ & $\begin{array}{l}\text { Represália, reação à } \\
\text { separação ou ciúmes }\end{array}$ & $\begin{array}{l}\text { Represália, autodefesa } \\
\text { ou seguro de vida }\end{array}$ \\
\hline $\begin{array}{l}\text { Consultas com } \\
\text { profissional da } \\
\text { saúde (ano que } \\
\text { precede o } \\
\text { homicídio) }\end{array}$ & Não & Sim \\
\hline $\begin{array}{l}\text { Transtorno } \\
\text { psicológico mais } \\
\text { frequente }\end{array}$ & $\begin{array}{l}\text { Transtorno da } \\
\text { personalidade }\end{array}$ & Transtorno clínico \\
\hline
\end{tabular}

\section{Considerações finais}

A partir das diferenças observadas, foi possível estabelecer um perfil dos homens e mulheres que cometeram o homicídio de sua(seu) companheira(o). Entre as diferenças mais significativas, observou-se que: as mulheres eram mais jovens que seus agressores e sua vítima; as mulheres homicidas eram mais escolarizadas que os homens homicidas; um número maior de homens homicidas estava empregado; os homens eram mais frequentemente os instigadores da violência conjugal e a mulher homicida, a vítima dessa violência; os homens apresentavam maior frequência de gestos autodestrutivos. Além disso, a violência conjugal, a separação, o abuso de álcool e os transtornos psicológicos ou psicopatológicos 
foram variáveis observadas que poderiam ter um impacto para a compreensão e a prevenção desse tipo de passagem ao ato homicida. Entretanto, várias semelhanças foram observadas nos dois grupos. Eis algumas delas: presença de outros tipos de atos de violência (criminais) e mesmo o fato de que os agressores masculinos ou femininos, em alguns casos, mas em proporções diferentes, podem ser tanto os instigadores como as vítimas da violência conjugal. Tais semelhanças remetem à ideia frequentemente desenvolvida por alguns autores - Senninger e Fontaa (1996) e Bergeret (1994, 1998) - de que a agressividade é universal, independentemente do sexo da pessoa que a exprime. É o percurso dessa agressividade, sua organização, sua inscrição nas relações interpessoais e sua compreensão social que gradualmente diferenciariam homens e mulheres. Assim, o encontro entre várias disciplinas contribuirá para uma compreensão mais abrangente das diferenças quanto à expressão dessa agressividade, e sua prevenção.

\section{Referências bibliográficas}

BÉNÉZECH, M. Classification des homicides volontaires et psychiatrie. Annales Medico-Psychologiques, v. 154, n. 2, p. 161-173, 1996. BERGERET, J. Actes de violence: réflexion générale. In. Millaud (Org.), Le passage à l'acte. Aspects cliniques et psychodynamiques. Paris: Masson, 1998. P. 9-14.

BERGERET, J. La violence et la vie. La face cachée de l'Oedipe. Paris: BSP, 1994.

DUBÉ, M., HODGINS, S. Grille d'analyse multidimensionnelle du filicide parental. In : Dubé, $M$. Étude rétrospective des facteurs de risque et des indices comportementaux précurseurs de filicide chez une cohorte de parents québécois. Tese (Doutorado em Psicologia), Université de Montréal, Montréal, 1998.

DUTTON, D. G. The neurobiology of abandonment homicide. Aggression and Violent Behavior, v. 7, n. 4, p. 407-421, 2001.

DUTTON, D. G. The Abusive Personality. Violence and Control in Intimate Relationships. New York: Guilford Press, 1998.

HOUEL, A.; MERCADER, P.; SOBOTA, H. Crime passionnel, crime ordinaire. Paris: Presses Universitaires de France, 2003.

FISCHER, G. N. Psychologie des violences sociales. Paris: Dunod, 2003.

FRIGON, S.; VIAU, L. Les femmes condamnées pour homicide et l'Examen de la légitime défense (Rapport Ratushny): portée juridique et sociale. Criminologie, v. 33, n. 1, p. 97-119, 2000.

SINNINGER, J.-L., FONTAA, V. Psychopathologie des malades dangereux. Paris: Dunod, 1996.

WEBSDALE, N. Understanding domestic homicide. Boston: Northeastern University Press, 1999. 
WILSON, M.; DALY, M. Spousal homicide risk and estrangement. Violence and Victims, v. 8, n. 1, p. 3-16, 1993.

\section{Endereço para correspondência}

Lucienne Martins Borges

Universidade Federal de Paraná, Departamento de Psicologia, Praça XV de Novembro, 1299, CEP 80060-000, Centro, Curitiba - PR, Brasil

Endereço eletrônico: lucienneborges@ufpr.br ou lucienne.martinsborges@psy.ulaval.ca

Recebido em: 08/10/2009

Aceito para publicação em: 28/10/2009

Acompanhamento do processo editorial: Adriana Benevides Soares

\section{Notas}

*Ph. D., Université Laval, École de Psychologie, Pesquisador colaborador

1 Resumo de tese de doutorado, concluída em 2006, sob orientação de Suzanne Léveillée. Titulo original: L'homicide commis dans une relation d'intimité: comparaisons selon le sexe des agresseurs. Tese de doutorado. Université du Québec à Trois-Rivières, 2006, 372 p.

2 Protocolo de Análise Multidimensional do Homicídio Conjugal

${ }^{3}$ Magistrado que investiga mortes suspeitas; Ministério de Segurança Pública do Québec. 